memo (2020) 13:5-6

https://doi.org/10.1007/s12254-019-00568-x

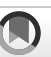

Check for

\section{Evidence-based follow-up}

\author{
Ewald Wöll
}

Received: 17 December 2019 / Accepted: 20 December 2019

(C) Springer-Verlag GmbH Austria, part of Springer Nature 2020

Although follow-up after primary treatment of cancer patients is our daily business, very few evidence-based strategies on the best modalities and time lines have been published so far.

Several medical societies however have issued their recommendations most often based on single institution experience or general common sense rather than evidence. Stringent follow-up however could lead to early detection of local or systemic relapse and possibly lead to better local control or even cure in oligometastatic disease. In a palliative setting, early detection of progress could result in more treatment options or possibly better symptom control. Even in patients who are in complete remission after several years of follow-up, the detection and management of late treatment toxicities including secondary neoplasms is an issue. However these questions have not been explored in a prospective setting very often.

In this issue of $M E M O$ six papers address these questions and reflect on existing guidelines, the current literature as well as psychosocial aspects and patient counseling.

Thomas Spanberger [1] addresses in his article both Hodgkin's lymphoma and aggressive non-Hodgkin's lymphoma and summarizes the evidence and recommendations on follow-up for these entities with a special focus on late toxicities.

Michael Stierer [2] provides insight into follow-up strategies in breast cancer with a special emphasis on early detection, management of treatment side effects and toxicities, patient motivation, psychosocial rehabilitation and lifestyle counseling.

\section{E. Wöll, MD (凶)}

St. Vinzenz Krankenhaus Betriebs GmbH,

Sanatoriumstraße 43, 6511 Zams, Austria

e.woell@krankenhaus-zams.at
Alexander Perathoner [3] sheds light on evidencebased follow-up in colorectal cancer and propagates patient-centered surveillance.

Stefan Watzka [4] illustrates follow-up strategies in non-small cell lung cancer emphasizing a more intense routine follow-up during the first two years after treatment, followed by less frequent regular visits throughout life.

Florian Kocher et al. [5] give a comprehensive overview about follow-up strategies in the risk group of recently operated lung cancer patients. They point out that standards differ substantially and that generally accepted follow-up recommendations are lacking.

Finally Karl Mayrhofer [6] focuses on follow-up in renal cell carcinoma. He reflects on the use of different imaging modalities, follow-up intervals with their effect on survival and patient outcomes.

I express my gratitude to the authors who have mastered this difficult task and congratulate them to their work. I am sure that you will find their contributions interesting and helpful.

Conflict of interest E. Wöll declares that he has no competing interests.

\section{References}

1. Spanberger T. Evidence-based follow-up in patients with Hodgkin's lymphoma and aggressive B-cell non-Hodgkin's lymphoma. memo. 2020. https://doi.org/10.1007/s12254020-00570-8.

2. Stierer M. Evidence-based follow-up for breast cancer. memo. 2020. https://doi.org/10.1007/s12254-019-00531w.

3. Maglione M, Perathoner A. Evidence-based follow-up in colorectal cancer-quo vadis? memo. 2020. https://doi. org/10.1007/s12254-019-00553-4. 


\section{editorial}

4. Watzka S. Evidence-based follow-up in non-small-cell lung cancer. memo. 2020. https://doi.org/10.1007/s12254-01900566- $\mathrm{z}$.

5. NgC,PircherA,AugustinF, KocherF.Evidence-basedfollowup in lung cancer?Focusing on the risk group of recently operated patients. memo. 2020. https://doi.org/10.1007/ s12254-020-00575-3.

6. Mayrhofer K, Niedersüß-BekeD. Evidence-based follow-up in renal cell carcinoma. memo. 2020. https://doi.org/10. 1007/s12254-019-00540-9.

Publisher's Note Springer Nature remains neutral with regard to jurisdictional claims in published maps and institutional affiliations. 